\title{
Vision screening in newborns and early childhood
}

\author{
Sophie Jullien(D)
}

\begin{abstract}
We looked at existing recommendations and supporting evidence on the effectiveness of screening for visual disorders in newborns and small infants, and in children between six months and five years of age.

We conducted a literature search up to the 5th of August 2019 by using key terms and manual search in selected sources. We summarized the recommendations and the strength of the recommendations when and as reported by the authors. We summarized the main findings of systematic reviews with the certainty of the evidence as reported on the accuracy of screening tests for detecting visual alterations; the efficacy of treatment for improving visual acuity, school performance, and quality of life; and potential harms derived from vision screening and treating visual alterations.

Although there is little evidence supporting its validity and effectiveness, examining all newborns for congenital cataract and retinoblastoma through the red reflex examination is widely accepted due to the severity of both diseases and the good outcomes reached by early detection and treatment. Overall, there is a moderate certainty of evidence that visual screening in children between three and five years provides a moderate net benefit, as assessed by the US Preventive Services Task Force: vision screening tests are accurate for detecting amblyopia and its risk factors, and their treatment is associated with visual improvement. There is uncertain evidence on whether vision screening in children under three years of age provides net benefits. Among populations with a low prevalence of vision abnormalities, screening the youngest is associated with an increased rate of false positives, leading to unnecessary additional assessment.
\end{abstract}

Keywords: Vision screening, Congenital cataract, Retinoblastoma, Amblyopia, Strabismus

\section{Background}

\section{Introduction}

The World Health Organization (WHO) European Region is developing a new pocket book for primary health care for children and adolescents in Europe. This article is part of a series of reviews, which aim to summarize the existing recommendations and the most recent evidence on preventive interventions applied to children under five years of age to inform the $\mathrm{WHO}$ editorial group to make recommendations for health promotion in primary health care. In this article, we looked at existing recommendations and

Correspondence: sophjullien@gmail.com

The complete list of abbreviations can be accessed as supplementary file in https://doi.org/10.1186/s12887-021-02638-8

Barcelona Institute for Global Health, University of Barcelona, Barcelona, Spain supporting evidence on the effectiveness of screening for visual disorders in newborns and small infants, and in children between six months and five years of age.

\section{Why is vision screening important in newborns and early childhood?}

The aim of vision screening in newborns and early childhood is to detect abnormalities that could lead to severe visual impairment or permanent vision loss if left untreated.

\section{Context}

In newborns and small infants, congenital cataract and retinoblastoma are relatively infrequent but can potentially lead to vision loss and even death in the case of

(c) The Author(s). 2021 Open Access This article is licensed under a Creative Commons Attribution 4.0 International License, which permits use, sharing, adaptation, distribution and reproduction in any medium or format, as long as you give appropriate credit to the original author(s) and the source, provide a link to the Creative Commons licence, and indicate if changes were made. The images or other third party material in this article are included in the article's Creative Commons licence, unless indicated otherwise in a credit line to the material. If material is not included in the article's Creative Commons licence and your intended use is not permitted by statutory regulation or exceeds the permitted use, you will need to obtain permission directly from the copyright holder. To view a copy of this licence, visit http://creativecommons.org/licenses/by/4.0/. The Creative Commons Public Domain Dedication waiver (http://creativecommons.org/publicdomain/zero/1.0/) applies to the data made available in this article, unless otherwise stated in a credit line to the data. 
retinoblastoma. The median prevalence of congenital cataracts was estimated at 1.7 per 10,000 children globally and the incidence of retinoblastoma was estimated at 6.0 and 7.1 per 100,000 live births in Northern Europe [1-3]. Early identification of these disorders could lead to early treatment with improved outcomes.

In infancy and preschool age children, one of the leading causes of vision impairment is amblyopia, known as 'lazy eye', with an estimated prevalence between 1 and $5 \%[4,5]$. Amblyopia refers to a decrease in visual acuity from one or both eyes, that arises during the period of visual development and which is not attributed to a structural alteration of the eye or visual pathways. The main risk factors associated with amblyopia include strabismus (ocular misalignment), significant bilateral refractive errors that cause blurred vision (myopia, hyperopia, astigmatism), and anisometropia (asymmetric retractive error). Less common risk factors are vision deprivation caused by media opacity (such as cataracts) or ptosis. Amblyopia is more common in prematurity, low birth weight, and when there is a positive family history, as those are risk factors for developing amblyogenic factors [4, 5]. Amblyopia and its risk factors are unlikely to resolve spontaneously and, if untreated, they can result in not only vision loss, but also in other consequences such as accidents, poor reading ability and suffering from bullying, depression, anxiety, or poor selfesteem [6]. Screening preschool age children for vision impairment could help identify those who may benefit from early interventions to correct or improve vision.

\section{Key questions}

\section{Newborns and small infants}

1. Is screening for visual disorders in newborns and small infants associated with improved outcomes?

\section{Children between six months and five years of age}

2. How accurate are the screening tests for detecting strabismus, refractive errors, anisometropia, and amblyopia in primary care among children between six months and five years of age?

3. What are the potential harms derived from screening children between six months and five years of age for strabismus, refractive errors, anisometropia, and amblyopia?

4. Is treatment of strabismus, refractive errors, media opacity, and amblyopia in children between six months and five years of age effective for improving visual acuity, school performance, and quality of life?

5. What are the potential harms derived from treating strabismus, refractive errors, anisometropia, and amblyopia in children between six months and five years of age?

6. Is population-based screening in children between six months and five years of age effective for improving long-term visual acuity, school performance and quality of life?

\section{Search methods and selected manuscripts}

We described the search methods, data collection and data synthesis in the second paper of this supplement (Sophie Jullien, Gottfried Huss \& Ralf Weige. Supporting recommendations for childhood preventive interventions for primary health care: elaboration of evidence synthesis and lessons learnt. BMC Pediatrics. 2021. https://doi.org/10. 1186/s12887-021-02638-8).

The search was conducted on the 5th of August 2019, by manual search and by using the search term "vision screening", "vision test", "vision disorder", or "amblyopia". We included any document that addressed at least one of the key questions. The WHO has developed several strategies and promotional activities to address blindness and vision impairment worldwide [7]. This WHO World report will contain recommendations including comprehensive and integrated eye care with the objective of helping to decrease the burden of eye diseases and vision impairment globally. However, we did not find any specific recommendations on screening measures for children other than eye examination in newborns. We found recommendations and their supporting evidence from the US Preventive Services Task Force (USPSTF) (2017) and the PrevInfad workgroup (Spanish Association of Primary Care Pediatrics) (2016). We looked at the National Institute for Health and Care Excellence (NICE) and Centers for Disease Control and Prevention (CDC) guidelines, as well as the recommendations from the American Academy of Pediatrics (AAP) in collaboration with the American Academy of Ophthalmology (AAO), the Royal College of Paediatrics and Child Health (RCPCH), and the UK National Screening Committee, and we included the brief recommendations that each of them provided.

The supporting evidence document for the USPSTF included a systematic review on screening for amblyopia and its risk factors in children. We searched in the Cochrane library for the identification of other systematic reviews on any topic related to our key questions. By using the search terms cited above, the search returned 99 reviews and two protocols. By screening the titles and abstracts, we included seven systematic reviews that addressed any of the key questions, two on screening and five on treatment of vision impairment. Among the two reviews on screening, one was published in 2017 and looked at tests for detecting strabismus in children between 1 and 6 years of age in the community. The 
other review assessed vision screening for amblyopia in childhood. Although it was published in 2009, we decided to include it due to the relevance of the topic and the lack of updated Cochrane review addressing this question.

All the included manuscripts for revision in this article are displayed in Table 1.

\section{Existing recommendations}

We summarized the existing recommendations and the strength of recommendations as per their authors in Table 2.

\section{Existing evidence}

The USPSTF 2017 recommendations result from a systematic review that the USPSTF commissioned in order to update their 2011 recommendations on screening for amblyopia and its risk factors in children [6]. Overall, 40 studies reported in 46 manuscripts were included, addressing one or several of the authors' key questions on screening test accuracy, and benefits and harms of vision screening in children, and of treatment of amblyopia, its risk factors, and refractive error. For each key question, authors assessed the quality of each included study (good, fair or poor, although poor studies were excluded) and the overall strength of the body of evidence (high, moderate, low or insufficient) mentioned in the text as 'strength of the evidence' as per the review authors.

The supportive document developed from PrevInfad consists on a comprehensive summary of systematic reviews addressing these topics [5]. PrevInfad addressed visual screening for newborns and infants, and for children aged between 12 months and 5 years, while the systematic review conducted by Jonas et al. included children between 6 months and 5 years of age. In the present document, we decided to first address screening in newborns and small infants to address congenital cataracts and retinoblastoma, and then screening in children between 6 months and 5 years of age in order to be inclusive. It should be noted that the 6 or 12 months threshold is very unlikely to make any difference on the inclusion of the studies as there is very little evidence on this age group.

\section{Visual disorders screening in newborns and small infants} Congenital cataract and retinoblastoma cause opacities of the transparent media, which can be detected by a simple and safe ocular examination assessing the red reflex with an ophthalmoscope. Although there is little evidence supporting the validity of this examination or the effectiveness of screening both diseases, it is widely accepted to routinely search in the neonatal period for

Table 1 Included manuscripts for revision

\begin{tabular}{|c|c|}
\hline Sources & Final selected manuscripts \\
\hline \multicolumn{2}{|l|}{ Recommendations } \\
\hline WHO & None \\
\hline USPSTF & $\begin{array}{l}\text { - } 2017 \text { recommendations [4] } \\
\text { - Jonas } 2017 \text { - Evidence support and systematic review [6] }\end{array}$ \\
\hline Previnfad & - 2016 recommendations and supporting evidence [5] \\
\hline CDC & - Guidelines for children's vision health [8] \\
\hline NICE & - NICE clinical guidelines 2015 - Postnatal care up to 8 weeks after birth [9] \\
\hline AAP and AAO & $\begin{array}{l}\text { - } 2016 \text { recommendations [10] } \\
\text { - Pediatric Eye Evaluation Preferred Practice Pattern [11] }\end{array}$ \\
\hline $\mathrm{RCPCH}$ & - Identification of visual impairments (Book chapter with recommendations) [12] \\
\hline UK NSC & $\begin{array}{l}\text { - } 2013 \text { recommendations [13] } \\
\text { - Childhood vision screening. External review against programme appraisal criteria } \\
\text { for the UK National Screening Committee } 2019 \text { [14] }\end{array}$ \\
\hline \multicolumn{2}{|l|}{ Systematic reviews } \\
\hline Cochrane Library & $\begin{array}{l}\text { - Antonio-Santos } 2014 \text { - Occlusion for stimulus deprivation amblyopia (Review) [15] } \\
\text { - Hull } 2017 \text { - Tests for detecting strabismus in children aged } 1 \text { to } 6 \text { years in the } \\
\text { community (Review) [16] } \\
\text { - Korah } 2014 \text { - Strabismus surgery before versus after completion of amblyopia } \\
\text { therapy in children (Review) [17] } \\
\text { - Powell } 2009 \text { - Vision screening for amblyopia in childhood (Review) [18] } \\
\text { - Tailor } 2015 \text { - Binocular versus standard occlusion or blurring treatment for unilateral } \\
\text { amblyopia in children aged three to eight years (Review) [19] } \\
\text { - Taylor } 2014 \text { - Interventions for strabismic amblyopia (Review) [20] } \\
\text { - Taylor } 2012 \text { - Interventions for unilateral and bilateral refractive amblyopia (Review) [21] }\end{array}$ \\
\hline
\end{tabular}

Abbreviations: AAO American Academy of Ophthalmology, AAP American Academy of Pediatrics, CDC Centers for Disease Control and Prevention, NICE National Institute for Health and Care Excellence, Previnfad PrevInfad workgroup from the Spanish Association of Primary Care Pediatrics, RCPCH Royal College of Paediatrics and Child Health, UK NSC UK National Screening Committee, USPSTF US Preventive Services Task Force, WHO World Health Organization 
Table 2 Summary of existing recommendations

\begin{tabular}{|c|c|c|c|c|c|}
\hline \multirow[t]{2}{*}{ Source } & \multirow[t]{2}{*}{ Ref } & \multirow[t]{2}{*}{ Date } & \multicolumn{3}{|c|}{ General recommendations for vision screening in children ${ }^{a}$} \\
\hline & & & Newborns and infants $<6$ months & Children 6 months to 3 years of age & Children $3-5$ years of age \\
\hline USPSTF & [4] & 2017 & - & $\begin{array}{l}\text { "The USPSTF concludes that the } \\
\text { current evidence is insufficient to } \\
\text { assess the balance of benefits and } \\
\text { harms of vision screening in children } \\
\text { younger than } 3 \text { years." (I Statement) }\end{array}$ & $\begin{array}{l}\text { "The USPSTF recommends vision } \\
\text { screening at least once in all children } \\
\text { aged } 3 \text { to } 5 \text { years to detect } \\
\text { amblyopia or its risk factors." (Grade } \\
\text { B recommendation) }\end{array}$ \\
\hline Prevlnfad & [5] & 2016 & $\begin{array}{l}\text { "PrevInfad recommends ocular } \\
\text { inspection and red reflex test in each } \\
\text { well-child visit on the first six months } \\
\text { of life, considering that, although the } \\
\text { quality of evidence is poor, the ex- } \\
\text { pected balance of the intervention is }\end{array}$ & - & $\begin{array}{l}\text { "Previnfad recommends visual } \\
\text { disorders screening (amblyopia, } \\
\text { strabismus and refraction errors) at } \\
\text { the age of } 3 \text { to } 5 \text { years old." (Grade } B \\
\text { recommendation) }\end{array}$ \\
\hline
\end{tabular}
probably positive.

(Grade of recommendation: given that the red reflex test does not meet the necessary conditions to be considered a screening test, it is not possible to establish a grade of recommendation for the newborns and infants' visual disorders screening.)"

CDC [8] 2019
'Prevent
blindness'

Newborns should have their eyes checked while still in the hospital nursery. This examination in the nursery should be for general eye health and include a red reflex test. This examination can help detect several congenital eye problems, some of which can be very serious and permanently threaten vision.
"Appropriate recommendations made by the UK National Screening Committee should also be carried out. A physical examination should also be carried out. This should include checking the baby's: [...] eyes; check opacities and red reflex [...]."

$\begin{array}{lll}\text { AAP and } & {[10,} & 2016 \\ \text { AAO }^{\mathbf{b}} & 11]\end{array}$

RCPCH [12] 2019
"Examination of the eyes and visual system should begin in the nursery and continue throughout both childhood and adolescence during routine well-child visits in the medical home."
During regular well baby exams, from birth to 3 years of age: Pediatricians should use family vision history and a vision assessment to see if vision problems exist.
Beginning at well child exams at age 3 and continuing annually through 10 years of age, vision screenings should be performed assessing your child's visual acuity and ocular alignment

If a child fails a vision screening or there is any concern of an eye or vision problem: The child should be referred for a comprehensive professional eye examination. This combination of vision screenings with referral for a comprehensive professional eye examination are the recommendations of the American Academy of Pediatrics, the American Academy of Ophthalmology, and the American Association for Pediatric Ophthalmology and Strabismus. The American Optometric Association supports a comprehensive professional eye examination performed by an eye doctor at age 6 months, 3 years and 5 years for all children.

$-$
- At 6 and 12 months: ocular history, external inspection of lids and eyes, red reflex testing, pupil examination, ocular motility assessment (12
months), and visual acuity fixate and follow response.
- From 1 to 3 years of age: all the above and instrument-based screen- ing when available. "Visual acuity screening may be attempted in co- operative 3-year-old child"

- From 4 years of age: visual acuity

and all the above (prior age group).

"Examination of all babies' eyes for the red reflex should take place in the newborn examination." (Strong evidence $)^{c}$
"Assess visual acuity in all 4-5-year olds as recommended by the UK National Screening Committee."

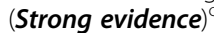

"Use evidence-based tests as part of the 4-5-year-old screening programme." (Strong evidence) ${ }^{c}$

"Alert parents to the signs of visual dysfunction, per the Personal Child Health Record." (Good practice) ${ }^{c}$ "Carry out specialist eye examinations at appropriate intervals in high-risk groups." (Strong evidence) ${ }^{c}$ 
Table 2 Summary of existing recommendations (Continued)

\begin{tabular}{llllll}
\hline Source & Ref & Date & \multicolumn{3}{l}{ General recommendations for vision screening in children ${ }^{\text {a }}$} \\
\cline { 3 - 5 } & & & Newborns and infants $<\mathbf{6}$ months & Children $\mathbf{6}$ months to $\mathbf{3}$ years of age & Children 3-5 years of age \\
\hline UK NSC & {$[13]$} & $\begin{array}{l}2013, \\
\text { updated } \\
\text { in } 2019\end{array}$ & - & "Screening of children's eyes should \\
continue to be offered to all children \\
aged $4-5$ years."
\end{tabular}

\begin{abstract}
Abbreviations: $A A O$ American Academy of Ophthalmology, AAP American Academy of Pediatrics, CDC Centers for Disease Control and Prevention, NICE National Institute for Health and Care Excellence, Prevlnfad PrevInfad workgroup from the Spanish Association of Primary Care Pediatrics, RCPCH Royal College of Paediatrics and Child Health, UK NSC UK National Screening Committee, USPSTF US Preventive Services Task Force

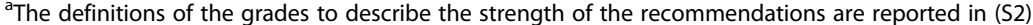

${ }^{b}$ Although the AAP and AAO did not report the strength of recommendations, authors specified that the recommendations were based on panel consensus

'The RCPCH rates the strength of the evidence as 'strong', 'moderately strong', and 'emerging'. Strong evidence is defined as evidence that is 'based on evaluations that are sufficiently rigorous to determine whether an intervention can be causally linked to improvements in outcomes. A reliable comparison group is needed, which is why randomized controlled trials are an important method of estimating impact'
\end{abstract}

opacities of the transparent media or leukocoria, as both disorders can be treated $[5,12]$.

From several national studies, screening newborns within the first six weeks of life detected between $47 \%$ (in the UK) and 75\% (in Sweden) of newborns with congenital cataract that needed surgery. It seems that the sensitivity of the red reflex to detect retinoblastoma is low, however the use of this low sensitivity screening tool is accepted in this case as it is a potentially lethal disorder and there is no alternative screening test as of today [5]. In addition, early diagnosis for early treatment is essential in both disorders. In the case of congenital cataract, surgery should be conducted within the first three months of age with the aim to achieve optimum outcome. Delay in the treatment can lead to irreversible amblyopia and consequent vision loss of the affected eye. In the case of retinoblastoma, it remains curable if treated within the first three to six months after the detection of leukocoria. Therefore, a child with leukocoria should be referred immediately. With early diagnosis and adequate treatment, the cure rate is up to $98 \%$ mostly with preservation of the vision, while survival will decrease with delay in the treatment [5].

Table 3 Available screening tests for visual impairment $[4,5]$

\begin{tabular}{lll}
\hline Visual impairment & Type of tests & Screening tests \\
\hline Visual acuity & Optotypes & $\begin{array}{l}\text { Picture identification tests } \\
\text { HOTV eye test } \\
\text { Snellen } \\
\text { Tumbling E }\end{array}$ \\
Strabismus & Ocular alignment tests & $\begin{array}{l}\text { Hirschberg test (corneal light reflex test) } \\
\text { Cover-uncover test (cross cover test) } \\
\text { Bruckner test (red reflex test) }\end{array}$ \\
Anisometropia & Stereoacuity test & $\begin{array}{l}\text { Stereo Smile } \\
\text { Random Dot E }\end{array}$ \\
& & TNO \\
Refractive errors & Instrument-based screening & $\begin{array}{l}\text { Photorefraction } \\
\text { Autorefractive screening } \\
\text { (computerized systems that allow objective } \\
\text { assessment of refractive errors) }\end{array}$ \\
& & Photo-screening (digitalized image)
\end{tabular}

One study was found that assessed cost-effectiveness of cataract screening in newborns. This study, conducted in Sweden, found that this screening performed in maternity wards after birth and during the routine health visits of the infant was cost-effective when compared to the screening performed only after birth [5].

\section{Accuracy of screening tests for detecting strabismus, refractive errors, anisometropia, and amblyopia in children under five years of age}

We summarized the main tests used for detecting strabismus, refractive errors, anisometropia and amblyopia in Table 3. Three systematic reviews addressed accuracy of these screening tests, which are summarized in Tables 4 and 5 .

\section{Influence of age in accuracy and testability of screening tests}

The screening of low age children could lead to an increased rate of false positives. In addition, the youngest might present less ability to complete the screening test, known as testability [5]. Jonas et al. included five studies that looked at the variation of the accuracy of visual acuity tests, a combination of clinical tests, an autorefractor 
Table 4 Systematic reviews on accuracy of vision screening tests

\begin{tabular}{|c|c|c|c|c|}
\hline \multirow{2}{*}{$\begin{array}{l}\text { Systematic } \\
\text { review }\end{array}$} & \multirow[t]{2}{*}{ Objective } & \multicolumn{2}{|l|}{ Methods } & \multirow[t]{2}{*}{ Number of manuscripts included } \\
\hline & & $\begin{array}{l}\text { Date of } \\
\text { literature } \\
\text { search }\end{array}$ & Inclusion criteria & \\
\hline $\begin{array}{l}\text { Powell } 2009 \\
{[18]}\end{array}$ & $\begin{array}{l}\text { To evaluate the effectiveness of vision } \\
\text { screening in reducing the prevalence } \\
\text { of amblyopia }\end{array}$ & $\begin{array}{l}\text { August } \\
2008\end{array}$ & $\begin{array}{l}\text { Randomised controlled trials (RCTs) or } \\
\text { cluster RCTs comparing the prevalence } \\
\text { of amblyopia in screened versus } \\
\text { unscreened populations } 12 \text { months } \\
\text { from screening }\end{array}$ & None \\
\hline $\begin{array}{l}\text { Hull } 2017 \\
{[16]}\end{array}$ & $\begin{array}{l}\text { To assess and compare the accuracy of } \\
\text { tests, alone or in combination, for } \\
\text { detection of strabismus in children } \\
\text { aged } 1 \text { to } 6 \text { years, in a community } \\
\text { setting by non-expert screeners or pri- } \\
\text { mary care professionals to inform } \\
\text { healthcare commissioners setting up } \\
\text { childhood screening programmes }\end{array}$ & $\begin{array}{l}\text { January } \\
2017\end{array}$ & $\begin{array}{l}\text { Prospective and retrospective } \\
\text { population-based studies evaluating } \\
\text { diagnostic test accuracy in consecutive } \\
\text { participants }\end{array}$ & $\begin{array}{l}1 \text { study, (Arthur 2009), which looked at } \\
\text { the effectiveness of automated photo- } \\
\text { screener for the detection of strabismus } \\
\text { [22]. This study was also included in Jo- } \\
\text { nas } 2017 \text {. }\end{array}$ \\
\hline $\begin{array}{l}\text { Jonas } 2017 \\
{[6]}\end{array}$ & $\begin{array}{l}\text { To assess the accuracy of the several } \\
\text { screening tests }\end{array}$ & June 2016 & $\begin{array}{l}\text { - Children aged } 6 \text { months to } 5 \text { years } \\
\text { - Studies conducted in countries } \\
\text { categorized as "very high" on the } \\
\text { United Nations Human Development } \\
\text { Index } \\
\text { - Publication in English language } \\
\text { - Good or fair quality of studies }\end{array}$ & $\begin{array}{l}34 \text { studies, conducted in Europe ( } 7 \\
\text { studies), the United States ( } 19 \text { studies), } \\
\text { Canada ( } 5 \text { studies) and Australia or } \\
\text { New Zealand ( } 3 \text { studies). } \\
\text { The strength of the evidence rated by } \\
\text { the review authors based on the } 34 \\
\text { included studies ( } 45,588 \text { observations) } \\
\text { was low. }\end{array}$ \\
\hline
\end{tabular}

and two photo-screeners due to age $[4,6]$. They found that children under the age of three were not included in most of the studies. They reached the conclusion that 'overall, data were limited and estimates were somewhat imprecise, but studies did not find any clear differences in test accuracy when results were stratified by age.'

Although testability is reported in many studies included in the Jonas et al. review, few of them reported their findings stratified by age, or for children under three years of age $[4,6]$. Testability was over $90 \%$ in most of the studies, and under $80 \%$ in few studies (all the studies with testability under $80 \%$ included children under three years of age). Higher testability rates were found in older children, and testability rates for visual acuity and stereoacuity tests were lower among children under the age of three. From the VIP study, testability of Lea and HOTV optotypes was over 95\% among children between 3 and 5 years, and testability of the Random Dot E was 86 and 93\% among 3 and 5-year-old children respectively. For autorefractors and photo-screeners, testability rate were close to $100 \%$ among children aged 3 years or above [4-6].

\section{Potential harms of screening children between six months and five years of age for strabismus, refractive errors, anisometropia and amblyopia}

False-positive findings in visual screening would lead to unnecessary referrals, and the associated anxiety and costs for the families and the health system. Jonas et al. reported the false-positive rates calculated from 16 studies [6]. They found false-positive rates above $75 \%$ in studies with a low prevalence of vision abnormalities (under 10\%), and between 5 and $39 \%$ in populations with a high prevalence of vision abnormalities (above 20\%) [4-6].

One controlled study identified by Jonas et al. evaluated the potential psychosocial effects of visual screening [23]. This prospective study compared bullying victimization ( $\geq 4$ times a month) by the age of 8 among children who were patched between two groups of schools: one group that received preschool screening for amblyopia and one group that did not. Among the included 4473 children, 122 were patched. The reduction in bullying victimization among children who were offered preschool screening compared to the control group was almost 50\% $(25.7 \%$ versus 47.1\%, with an AOR 0.39 [95\%CI 0.16 to 0.92], adjusted for sex, paternal socioeconomic class, highest level of maternal education, and type of housing). Early screening leading to early intervention was associated with a decreased risk of bullying among patched children, probably because children are younger by the time they can remove the patch.

Based on the 16 observational studies and the cohort study included in the Jonas et al. review (14,196 observations), the strength of the evidence was rated as low for bullying, moderate for false-positive rates, and insufficient for other harms.

No studies were found that assessed possible harms derived from wearing glasses when unnecessary (long term outcomes and impacts in the vision), nor that evaluated rate of children who received unnecessary treatment for amblyopia or any of its risk factors $[4,5]$. 
Table 5 Main findings on accuracy of vision screening tests

\begin{tabular}{|c|c|c|}
\hline Screening tests for visual impairment & Included studies & Main findings \\
\hline $\begin{array}{l}\text { Visual acuity tests (assessment of picture } \\
\text { identification tests (LEA Symbols chart) and } \\
\text { HOTV eye test) }\end{array}$ & 6 studies [6] & $\begin{array}{l}\text { When screening test cut-offs were set to achieve specificities of } \\
\text { 90\%: } \\
\text { - Positive LR: } 6.1 \text { ( } 95 \% \text { Cl } 4.8 \text { to } 7.6 \text { ); 'an abnormal result moderately } \\
\text { increased the likelihood of amblyopia, amblyopia risk factors } \\
\text { (strabismus, astigmatism, hyperopia, myopia, anisometropia), or } \\
\text { significant nonamblyogenic refractive error' } \\
\text { - Negative LR: } 0.43 \text { ( } 95 \% \text { Cl } 0.38 \text { to 0.50); 'a normal result indicated a } \\
\text { small decrease in the likelihood' }\end{array}$ \\
\hline \multirow[t]{2}{*}{$\begin{array}{l}\text { Ocular alignment tests } \\
\text { (Cover-uncover test) }\end{array}$} & 1 study [6] $(n=3121)$ & $\begin{array}{l}\text { Sensitivity to detect strabismus was } 60 \% \text { for specificity set to } 90 \% \\
\text { - Positive LR: } 7.9 \text { ( } 95 \% \text { Cl } 4.6 \text { to } 14.0) \\
\text { - Negative LR: } 0.73 \text { ( } 95 \% \text { Cl } 0.15 \text { to } 0.85)\end{array}$ \\
\hline & 1 study [5] & $\begin{array}{l}\text { For detecting strabismus in children at } 37 \text { months: } \\
\text { - Sensitivity of } 75 \%(95 \% \mathrm{Cl}: 57.7 \text { to } 89.9 \%) \\
\text { - Specificity of } 100 \%\end{array}$ \\
\hline Stereoacuity tests & 4 studies [6] $(n=7801)$ & $\begin{array}{l}\text { - Positive LRs: range from } 3.6 \text { to } 4.9 \\
\text { - Negative LRs: in the minimal range for detecting amblyopia risk } \\
\text { factors or significant nonamblyogenic refractive error and in the } \\
\text { moderate range for detecting refractive error or strabismus }\end{array}$ \\
\hline $\begin{array}{l}\text { Combination of clinical tests } \\
\text { (visual acuity, ocular alignment and } \\
\text { stereoacuity tests) }\end{array}$ & 4 studies $[4-6](n=1854)$ & $\begin{array}{l}\text { - Positive LRs: median of } 14 ; \text { range from } 12 \text { to } 17 \text { ( } 3 \text { studies); } 4.8 \\
\text { ( } 95 \% \text { Cl } 2.8 \text { to } 8.4 ; 1 \text { study; } n=141 \text { ) } \\
\text { - Negative LRs: median of } 0.28 ; \text { range from } 0.10 \text { to } 0.91 \\
\text { - In one study, the cover-uncover test performed by professionals } \\
\text { or a stereoacuity test showed an increased detection of strabis- } \\
\text { mus when combined with visual acuity tests. }\end{array}$ \\
\hline Autorefractors & $\begin{array}{l}16 \text { studies }[6](n=16,712)(5 \\
\text { studies recruited children }<3 \\
\text { years of age) }\end{array}$ & $\begin{array}{l}\text { - Positive LRs: 'most studies reported moderate positive LRs', 'some } \\
\text { studies reported large positive LRs' } \\
\text { - Negative LRs: 'most studies reported small negative LRs', 'some } \\
\text { studies reported large negative LRs' }\end{array}$ \\
\hline \multirow[t]{2}{*}{ Photo-screeners } & 11 studies [6] $(n=6187)$ & $\begin{array}{l}\text { - Positive LRs: 'most studies reported moderate positive LRs' } \\
\text { - Negative LRs: 'most studies reported small negative LRs' }\end{array}$ \\
\hline & 1 study [16] & $\begin{array}{l}\text { Prospective study that evaluated the diagnostic accuracy of a } \\
\text { digital photo-screener in a school screening programme in Canada } \\
{[16,22] \text {. Among the } 335 \text { recruited children ( } 98 \% \text { were } 4 \text { or } 5 \text { years }} \\
\text { of age), } 271 \text { completed both the screening test and the reference } \\
\text { standard test (ophthalmic examination by a physician who was } \\
\text { blinded to the photo-screening findings). Results from both tests } \\
\text { agreed in } 94 \% \text { of cases. } \\
\text { - Sensitivity and specificity in detecting amblyopia risk factors were } \\
83 \text { and } 95 \% \text { respectively } \\
\text { - Positive and negative predictive values were } 73 \text { and } 97 \% \text {, } \\
\text { respectively. } \\
\text { When looking more specifically at detection of strabismus, } \\
\text { sensitivity and specificity were } 46 \text { and } 97 \% \text { respectively, with } 13 \\
\text { children detected by reference standard test. The estimated } \\
\text { prevalence of strabismus in the population was } 4.8 \% \text {. }\end{array}$ \\
\hline $\begin{array}{l}\text { Retinal birefringence scanning } \\
\text { (assessment of the Pediatric Vision Scanner } \\
\text { (REBIScan)) }\end{array}$ & 1 study [6] $(n=102)$ & $\begin{array}{l}\text { - Positive LR: } 10.4 \text { (95\% Cl } 5.6 \text { to 19.4) } \\
\text { - Negative LR: } 0.0\end{array}$ \\
\hline
\end{tabular}

Abbreviations: $\mathrm{Cl}$ confidence interval, $L R$ likelihood ratio

\section{Effectiveness of treatment of strabismus, refractive errors, anisometropia, and amblyopia in children between six months and five years of age}

The success of the visual screening will partly depend on the effectiveness of the treatment to improve or correct amblyopia and its risk factors, in order to improve visual acuity, avoid permanent vision loss, and subsequently to improve school performance and functionality for a better quality of life. There are however no studies evaluating school performance or other functional outcomes, or quality of life [4]. There are several treatment strategies for treating amblyopia, including the correction of refractive errors by using glasses, with the addition or not of occlusive patches, opaque lens or eye drops to blur the better seeing eye. Several factors could influence the effectiveness of the treatment: age of the child when starting the treatment, the intensity of amblyopia, and therapeutic compliance [5].

We summarized the main findings on the effectiveness of different interventions for vision impairment in 
Table 6 Systematic reviews on treatment effectiveness

\begin{tabular}{|c|c|c|c|}
\hline \multirow{2}{*}{$\begin{array}{l}\text { Syste- } \\
\text { matic } \\
\text { review }\end{array}$} & \multirow[t]{2}{*}{ Objective } & \multicolumn{2}{|l|}{ Methods } \\
\hline & & $\begin{array}{l}\text { Date of } \\
\text { literature } \\
\text { search }\end{array}$ & Inclusion criteria \\
\hline $\begin{array}{l}\text { Jonas } \\
2017 \text { [6] }\end{array}$ & $\begin{array}{l}\text { To assess effectiveness of treatment of } \\
\text { amblyopia, its risk factors, and refractive } \\
\text { error }\end{array}$ & June 2016 & $\begin{array}{l}\text { - Children aged } 6 \text { months to } 5 \text { years } \\
\text { - Studies conducted in countries } \\
\text { categorized as "very high" on the } \\
\text { United Nations Human } \\
\text { Development Index } \\
\text { - Publication in English language } \\
\text { - Good or fair quality of studies }\end{array}$ \\
\hline
\end{tabular}

Main findings

January

2014

treatment for strabismic amblyopia:

- Impact of conventional occlusion therapy

- Role of partial occlusion and optical penalisation
Taylor To evaluate the effectiveness of

2012 [21] spectacles, occlusion or both for the treatment of unilateral and bilateral refractive amblyopia
- Good or fair quality of studies

- 3 studies included, 2 conducted in the UK, 1 in the US.

- Comparison: 2 studies compared patching versus no patching (with continued eyeglasses in both groups if required); 1 study compared patching plus eyeglasses versus eyeglasses alone versus no intervention.

- Participants: mean age of 4 to 5.2 years and ranging from 3 to 8 years.

- Intervention: the duration of treatment was 5 and 12 weeks for the two studies comparing patching versus no patching with 52 weeks of follow-up in one of them, and one year of treatment for the third study comparing three arms, with 78 weeks of followup.

- Outcome measured: improvement in visual acuity.

- Findings: patching was associated with visual acuity improvement, although the effect was small.

- The review authors concluded that early treatment of amblyopia in children aged between 3 and 5 years improved vision, with greater benefits among children with more severe vision impairment at baseline.

- The strength of the evidence based on these three clinical trials $(n=417)$ was rated as moderate for improved visual acuity.

- RCTs for the treatment of strabismic amblyopia

- No age restriction

- No language or date restriction

- 3 studies included (of which 1 is included in Jonas 2017), conducted in the US. Of them, 2 studies assessed the effect of supplementing the occlusion therapy with near activities. - Occlusion in addition to refractive correction with eyeglasses when needed, 'appears to be more effective than refractive correction alone in the treatment of strabismic amblyopia' and that 'the benefit of combining near activities with occlusion is unproven'

January - RCTs - 8 studies included (of which 2 are

2012 - Treatment for unilateral and bilateral included in Jonas 2017) refractive amblyopia by spectacles, - No trials included children with

with or without occlusion bilateral amblyopia.

- No age restriction
- Meta-analysis could not be performed due to heterogeneity with a lack of data for each outcome.

- Overall, review authors concluded that 'in some cases of unilateral refractive amblyopia it appears that there is a treatment benefit from refractive correction alone' and that 'where amblyopia persists there is evidence that adding occlusion further improves vision' 
Table 6 Systematic reviews on treatment effectiveness (Continued)

\begin{tabular}{|c|c|c|c|c|}
\hline \multirow{2}{*}{$\begin{array}{l}\text { Syste- } \\
\text { matic } \\
\text { review }\end{array}$} & \multirow[t]{2}{*}{ Objective } & \multicolumn{2}{|l|}{ Methods } & \multirow[t]{2}{*}{ Main findings } \\
\hline & & $\begin{array}{l}\text { Date of } \\
\text { literature } \\
\text { search }\end{array}$ & Inclusion criteria & \\
\hline $\begin{array}{l}\text { Antonio- } \\
\text { Santos } \\
2014 \text { [15] }\end{array}$ & $\begin{array}{l}\text { To assess the effectiveness of occlusion } \\
\text { therapy for stimulus deprivation } \\
\text { amblyopia }\end{array}$ & October2013 & $\begin{array}{l}\text { - RCTs or quasi-RCTs } \\
\text { - Participants with unilateral stimulus } \\
\text { deprivation amblyopia } \\
\text { - No age restriction }\end{array}$ & $\begin{array}{l}\text { - No trial was found that fulfilled the } \\
\text { inclusion criteria. }\end{array}$ \\
\hline $\begin{array}{l}\text { Tailor } \\
2015 \text { [19] }\end{array}$ & $\begin{array}{l}\text { To determine whether binocular versus } \\
\text { standard occlusion or pharmacological } \\
\text { blurring treatment for unilateral } \\
\text { amblyopia in children between } 3 \text { and } 8 \\
\text { years of age }\end{array}$ & April 2015 & $\begin{array}{l}\text { - RCTs } \\
\text { - Participants between } 3 \text { and } 8 \text { years } \\
\text { of age with unilateral amblyopia } \\
\text { - Any type of binocular viewing } \\
\text { intervention }\end{array}$ & $\begin{array}{l}\text { - No trial was found that fulfilled the } \\
\text { inclusion criteria. }\end{array}$ \\
\hline $\begin{array}{l}\text { Korah } \\
2014 \text { [15] }\end{array}$ & $\begin{array}{l}\text { To assess strabismus surgery before } \\
\text { versus after completion of amblyopia } \\
\text { therapy on functional and anatomic } \\
\text { outcomes }\end{array}$ & July 2014 & $\begin{array}{l}\text { - RCTs } \\
\text { - Children < } 7 \text { years of age } \\
\text { - Comparison of strabismus surgery } \\
\text { before completion of amblyopia } \\
\text { therapy with strabismus surgery } \\
\text { after completion of amblyopia } \\
\text { therapy }\end{array}$ & $\begin{array}{l}\text { - No trial was found that fulfilled the } \\
\text { inclusion criteria. }\end{array}$ \\
\hline $\begin{array}{l}\text { Previnfad } \\
{[5]} \\
\text { UK NSC }\end{array}$ & $\begin{array}{l}\text { To address treatment of vision } \\
\text { impairment }\end{array}$ & & & $\begin{array}{l}\text { - } 19 \text { included studies } \\
\text { - Comparisons: } \\
\text { - } 7 \text { studies compared different regimens } \\
\text { of ocular occlusion with patches } \\
\text { - } 5 \text { studies compared blurring the vision } \\
\text { with atropine versus ocular occlusion } \\
\text { - } 1 \text { study compared blurring the vision } \\
\text { with atropine on a daily basis or } \\
\text { during weekends } \\
\text { - } 6 \text { studies assessed other interventions } \\
\text { - Main conclusions: } \\
\text { - There is no evidence of any specific } \\
\text { intervention being more effective } \\
\text { - More intensive occlusive treatment } \\
\text { with patches were beneficial to older } \\
\text { children and those with severe } \\
\text { amblyopia } \\
\text { - In children with moderate amblyopia, } \\
\text { blurring the eye with atropine twice } \\
\text { weekly and patching were similarly } \\
\text { effective, and the risk of local and } \\
\text { systemic adverse effects caused by } \\
\text { atropine are compensated by the } \\
\text { psychosocial effects of patching }\end{array}$ \\
\hline
\end{tabular}

Abbreviation: $R C T S$ randomized controlled trials

children from the USPSTF review, five Cochrane reviews, and an additional review from the UK National Screening Committee (NSC) that was identified in the PrevInfad document, in Table 6. The UK NSC review that was published in 2019 by the same authors to look at recent evidence to make evidence-based decisions on whether the 2012 recommendations from the UK NSC needed to be amended found no new evidence on these topics $[13,14]$.

\section{Influence of age in effectiveness of treatment}

Evidence on the impact of age in the effectiveness of treatment is controversial, and we report here findings from the PrevInfad summary document [5]. No clinical trial included children under three years of age. Among children between 3 and 6 years of age, most of the studies showed no association between age and effects of treatment. A meta-analysis of four trials conducted in the US including 996 children between 3 and 12 years of age, looked at three age groups: 3 to less than 5 years, 5 to less than 7 years, and 7 to less than 13 years. Treatment in the oldest group was less effective than in the other two groups $(p<0.04$ for moderate intensity amblyopia and $p<0.01$ for severe intensity amblyopia). There were no significant differences in treatment between the two younger groups for both moderate and severe intensity amblyopia, although there was a trend to a minor effect in older children with severe amblyopia. From another study, delaying patching by one year in children aged between three and five years was associated to poorer results after six months of follow-up. Another study compared less than three hours with three to six 
hours of daily occlusion in two age groups. There were no significant differences between the two regiments among children under four years $(p=0.54)$, but treatment was more effective with three to six hours daily occlusion among older children $(p=0.03$ in 4 to 6year-old children and $p<0.001$ in children older than 6 years).

Although it was considered that amblyopia was irreversible if left untreated until the age of 6-10 years, some studies have shown that treatment can be effective in older children, although effectiveness is less from the age of $7[5]$.

\section{Potential harms of treating strabismus, refractive errors, anisometropia, and amblyopia in children between six months and five years of age}

Potential harms derived from treatment of visual impairment were evaluated by the Jonas review and the PrevInfad document $[5,6]$. Some studies have associated the treatment of amblyopia with a reversible vision loss in the non-amblyopic eye. In one study, this was higher among children treated with occlusion, compared to atropine (decrease in visual acuity of two or more lines: RR 0.93 [95\% CI 0.88 to 0.97]). Another study also showed a decrease in the visual acuity of the nonamblyopic eye, which was higher among the group treated with atropine and flat lens compared to atropine alone (decrease in visual acuity of one or more lines: RR 0.86 [ $95 \%$ CI 0.78 to 0.95$]$ ). This loss in visual acuity was recovered in 19 out of the 20 affected children and in 17 out of the 18 affected children in the first and second study respectively. However, other studies showed no association between treatment and increased risk of vision loss in the non-amblyopic eye, such as two trials included in the Jonas review (one trial with patching and the other comparing eyeglasses plus patching versus eyeglasses alone versus no treatment) [5].

Two clinical trials included in the Jonas review assessed the psychosocial adverse effects of treatment for amblyopia. One trial found no differences on being happy, cooperative, or good tempered, on teasing, on problems at preschool, or in emotional and behavioural problems between three groups of 4-year-old children treated with patch and eyeglasses, eyeglasses alone, and no treatment. However, they found that children treated with patch and eyeglasses were more upset than those treated with eyeglasses alone $(85 \%$ versus $29 \%$ at 4 years of age $[p=0.03]$, and $62 \%$ versus $26 \%$ at 5 years of age $[p=0.005])$. The limitation of this study is the high attrition bias, with data available for only $44 \%$ of the recruited children. The other trial showed a decrease in the emotional well-being of children treated with atropine or patch, with a larger effect among patched children. Other observational studies evaluated the association between psychosocial effects and stigma and treatment of amblyopia, with diverging findings $[5,6]$.

Treatment with patches was associated with cutaneous irritation in 5\% of children included in one trial [5]. Another trial including 60 children comparing daily $3 \mathrm{~h}$ of patching, $6 \mathrm{~h}$ of patching and no treatment showed no inverse amblyopia and no patch allergy [6]. Some local and systemic adverse effects associated with atropine were also reported in some clinical trials [5].

The strength of the evidence rated by Jonas et al. based on the three clinical trials included for this topic $(n=417)$ was low.

\section{Effectiveness of population-based screening in children between six months and five years of age}

No RCT was found that assessed population-based screening for vision impairments in children versus no screening, looking at long-term outcomes such as amblyopia prevalence, schooling performance or quality of life [5]. The Jonas et al. review identified two studies (one RCT and one cohort study) conducted in England in 1991-92, that evaluated the prevalence of amblyopia at the age of 7.5 years [6]. The RCT recruited 3490 children and compared intensive orthoptist screening six times between 8 and 37 months and one time at 37 months of age. The risk of presenting amblyopia at 7.5 years was lower in the group with multiple times screening compared to single time screening ( $0.6 \%$ versus $1.8 \%$; RR 0.35 [ $95 \%$ CI: 0.15 to 0.86 ]), however this was only significant for one of the wo amblyopia definitions evaluated (interocular difference in acuity $\geq 0.3$ $\log$ MAR). Mean visual acuity in the worse eye after treatment (patching) was better among children screened several times versus a single time $(0.15$ versus $0.26 \log$ MAR; $p<0.0001$ ) [6]. The cohort study recruited 6081 children and compared single screening at 37 months of age in one health district versus no preschool screening in two other health districts. There were no significant differences in the prevalence of amblyopia at 7.5 years of age, assessed by three definitions. Both studies were at high risk of attrition bias. Indeed, data was available for only $55 \%$ of the recruited children at the end of the follow-up period [6]. In addition, the RCT was at high risk of selection bias as the method of randomization was inadequate and the baseline characteristics for amblyopia or its risk factors were not reported. Based on these two studies $(n=7795)$, the strength of the evidence was rated as low.

Few retrospective population-based studies found an association between vision screening and a reduced prevalence of amblyopia, but the low quality of methodology raises concern about the internal and external validity of these findings [5]. 
It is worth to mention that there is no evidence to determine the optimal vision screening interval in children under five years of age [4].

\section{Summary of findings}

- Although there is little evidence supporting the validity and effectiveness of examining all newborns for congenital cataract and retinoblastoma through the red reflex examination, examining routinely the eyes of all newborns is widely accepted due to the severity of both diseases, if left untreated, and the good outcomes reached by early detection and treatment.

- Visual tests used for screening children aged three to five years were assessed to be useful for detecting amblyopia and its risk factors. Estimates showed higher positive likelihood ratio for the detection of children at higher risk, and for the combination of clinical tests.

- Overall, there is a moderate certainty of evidence that visual screening in children between three and five years provides a moderate net benefit, as assessed by the US Preventive Services Task Force (USPSTF): vision screening tests are accurate for detecting amblyopia and its risk factors, and treatment of these visual abnormalities is associated with visual improvement.

- Overall, there is uncertain evidence on whether screening amblyopia and its risk factors in children under three years of age provides net benefits. Among populations with a low prevalence of vision abnormalities, screening the youngest is associated with an increased rate of false positives, leading to unnecessary additional assessment.

- There is limited evidence on harms from treatment, but patching may have some psychological harms.

- There are several gaps in the evidence to acquire a better understanding of the best combination of screening tests, the optimal age for initiation of screening, the optimal screening intervals, the net benefit of screening and treatment in children under three years of age, and the long-term outcomes of preschool screening such as school performance and quality of life.

\footnotetext{
Acknowledgments

I am very grateful to María Jesús Esparza, Laura Reali, and Gottfried Huss for carefully reviewing and providing valuable feedback for each article. I am also grateful to Ralf Weigel and Gottfried Huss for proofreading the final version of this document.
}

\section{About this supplement}

This article has been published as part of BMC Pediatrics Volume 21, Supplement 1 2021: Defined preventive interventions for children under five years of age: evidence summaries for primary health care in the WHO European region. The full contents of the supplement are available at https://bmcpediatrics.biomedcentral.com/articles/supplements/volume-21supplement-1.

\section{Author's contributions}

SJ was identified as the researcher in the development of the synthesis of evidence and writing the report. For each selected topic on preventive interventions, SJ defined the key questions, established and run the literature search, screened the returned manuscripts for eligibility, extracted data and summarized the existing recommendations and supporting evidence. The principal advisors of this project were Dr. Gottfried Huss, MPH General Secretary of ECPCP, Project- Coordinator and Prof. Ralf Weigel, Friede Springer endowed professorship of Global Child Health, Witten/Herdecke University (scientific advice). The author(s) read and approved the final manuscript.

\section{Funding}

Publication charges for this article have been funded by the Friede Springer endowed professorship for Global Child Health at the Witten Herdecke University, Germany.

Availability of data and materials

Not applicable.

\section{Declarations}

Ethics approval and consent to participate

Not applicable.

\section{Consent for publication}

Not applicable.

\section{Competing interests}

$\mathrm{SJ}$ had a contract and was paid as an independent consultant by the WHO via Witten/ Herdecke University, ECPCP and EPA/UNEPSA for developing the different articles of this supplement.

Published: 8 September 2021

\section{References}

1. Sheeladevi S, Lawrenson JG, Fielder AR, Suttle CM. Global prevalence of childhood cataract: a systematic review. Eye. 2016;30(9):1160-9. https://doi. org/10.1038/eye.2016.156.

2. Gregersen PA, Urbak SF, Funding M, Overgaard J, Jensen UB, Alsner J. Danish retinoblastoma patients 1943-2013 - genetic testing and clinical implications. Acta Oncol. 2016;55(4):412-7. https://doi.org/10.3109/02841 86X.2015.1099732

3. Seregard S, Lundell G, Svedberg $H$, Kivelä T. Incidence of retinoblastoma from 1958 to 1998 in northern Europe: advantages of birth cohort analysis. Ophtalmology. 2004;111(6):1228-32. https://doi. org/10.1016/j.ophtha.2003.10.023.

4. US Preventive Services Task Force. Vision screening in children aged 6 months to 5 years. US Preventive Services Task Force Recommendation Statement. JAMA. 2017;318(9):836-44.

5. García Aguado J. Visual screening in childhood. Recommendation [Internet]. Recomendations Previnfad/PAPPS. 2016 [cited 2019 Aug 5]. Available from: http://previnfad.aepap.org/monografia/vision

6. Jonas DE, Amick HR, Wallace IF, Feltner C, Vander Schaaf EB, Brown CL, Baker C. Vision screening in children aged 6 months to 5 years: evidence report and systematic review for the US preventive services task force. JAMA. 2017;318(9):845-58. https://doi.org/10.1001/jama.2017.9900.

7. Organization WH. Blindness and vision impairment [Internet]. 2019 [cited 2019 Aug 6]. Available from: https://www.who.int/blindness/en/

8. Prevent Blindness. Guidelines for children's vision health [Internet]. 2019 [cited 2019 Aug 5]. Available from: https://www.preventblindness.org/ guidelines-childrens-vision-health

9. National Institute for Health and Care Excellence (NICE). Postnatal care up to 8 weeks after birth (CG37). 2015.

10. Committee on Practice and Ambulatory Medicine Section on Ophthalmology, American Association of Certified Orthoptists, American Association for Pediatric Ophthalmology and Strabismus AA of O. Visual 
system assessment in infants, children, and young adults by pediatricians. Pediatrics. 2016;137(1):e20153596.

11. American Academy of Ophthalmology. Pediatric eye evaluations preferred practice pattern [Internet]. 2017 [cited 2019 Aug 5]. Available from: https:// www.aao.org/preferred-practice-pattern/pediatric-eye-evaluations-ppp-2017

12. Solebo AL. Identification of visual impairments. In: Health for all children. Fifth; 2019. p. 246-57.

13. Committee UNS. Vision defects screening in children [Internet]. Screening in the UK: making effective recommendations. 2014 [cited 2019 Aug 5]. Available from: https://www.gov.uk/government/publications/uk-nationalscreening-committee-recommendations-annual-report

14. Solebo AL, Rahi JS. Childhood vision screening. In: External review against programme appraisal criteria for the UK National Screening Committee (UK NSC) [Internet]; 2019. [cited 2019 Aug 5]. Available from: https://lega cyscreening.phe.org.uk/vision-child.

15. Antonio-Santos A, Vedula S, Hatt S, Powell C. Occlusion for stimulus deprivation amblyopia (Review). Cochrane Database Syst Rev. 2014;2(Art): No.: CD005136.

16. Hull S, Tailor V, Balduzzi S, Rahi J, Schmucker C, Virgili G. Tests for detecting strabismus in children aged 1 to 6 years in the community (Review). Cochrane Database Syst Rev. 2017;11(Art):No.: CD011221.

17. Korah S, Philip S, Jasper S, Braganza A. Strabismus surgery before versus after completion of amblyopia therapy in children (Review). Cochrane Database Syst Rev. 2014;10(Art):No.: CD009272.

18. Powell C, Hatt S. Vision screening for amblyopia in childhood (Review). Cochrane Database Syst Rev. 2009:3(Art):No.: CD005020.

19. Tailor V, Bossi M, Bunce C, Greenwood J, Dahlmann-Noor A. Binocular versus standard occlusion or blurring treatment for unilateral amblyopia in children aged three to eight years (Review). Cochrane Database Syst Rev. 2015;8(Art):No.: CD011347.

20. Taylor K, Elliott S. Interventions for strabismic amblyopia (Review). Cochrane Database Syst Rev. 2014;7(Art):No.: CD006461.

21. Taylor K, Powell C, Hatt S, Stewart C. Interventions for unilateral and bilateral refractive amblyopia (Review). Cochrane Database Syst Rev. 2012;4(Art):No: CD005137.

22. Arthur BW, Riyaz R, Rodriguez S, Wong J. Field testing of the plusoptiX S04 photoscreener. J AAPOS [Internet]. 2009;13(1):51-7 Available from: http://dx. doi.org/10.1016/j.jaapos.2008.08.016.

23. Williams C, Horwood J, Northstone K, Herrick D, Waylen A, Wolke D, ALSPAC Study Group. The timing of patching treatment and a child's wellbeing. Br J Ophthalmol. 2006;90(6):670-1. https://doi.org/10.1136/bjo.2006.091082.

\section{Publisher's Note}

Springer Nature remains neutral with regard to jurisdictional claims in published maps and institutional affiliations.

Ready to submit your research? Choose BMC and benefit from:

- fast, convenient online submission

- thorough peer review by experienced researchers in your field

- rapid publication on acceptance

- support for research data, including large and complex data types

- gold Open Access which fosters wider collaboration and increased citations

- maximum visibility for your research: over $100 \mathrm{M}$ website views per year

At $\mathrm{BMC}$, research is always in progress.

Learn more biomedcentral.com/submissions 